\title{
A filosofia em cena: crítica e afirmação da teatralidade em Nietzsche ${ }^{*}$
}

\author{
Diego Sánchez Meca**
}

\begin{abstract}
Resumo: O propósito deste artigo é mostrar a contribuição de Nietzsche à revolução nas práticas da encenação que ocorreram no Século XX, bem como sua relevância como crítico apaixonado pelo potencial de uma forma de arte que ele sentia que era interpretada em sua época de forma diminuída. A partir de seu estudo do teatro grego na obra $O$ nascimento da tragédia, sublinha a importância da encenação na tragédia antiga, a qual estava para além do texto escrito por seu autor. Oferece com isso uma análise da ideia de teatro como arte, a qual é consubstancial realizar-se em três dimensões: a do ator, a do poeta ou escritor do texto e a do espectador. Nietzsche defende a especificidade desses três papéis para toda realização teatral e o sentido filosófico que tem o teatro como autêntica forma artística. Conclui-se o artigo mostrando a recepção do pensamento teatral de Nietzsche em autores como August Strindberg, George Bernard Shaw e Eugene O'Neill, que buscarão novas formas e novos significados para sua arte.
\end{abstract}

Palavras-Chave: teatro, Nietzsche, filosofia, arte, encenação.

* Tradução de Márcio José Silveira Lima.

**Universidade Complutense, UNED, Madri, Espanha.

ORCID https://orcid.org/0000-0001-6531-7365

Correio eletrônico: dsanchez@fsof.uned.es 
Sánchez Meca, D.

\section{O teatro, um desafio para a filosofia?}

Em si, o teatro representa, sem dúvida, um certo desafio para a filosofia, sobretudo quando se entende a filosofia em seu sentido mais clássico, ou seja, como uma investigação racional acerca da verdade. Em uma entrevista publicada em 1978 e intitulada $A$ cena da filosofia, Foucault denunciava o desinteresse que, em geral, a filosofia ocidental havia mostrado sempre pelo teatro desde a condenação que já lhe fizera Platão ${ }^{1}$. Sem dúvida, a originalidade de Nietzsche consistiu - disse Foucault - em converter a relação entre filosofia e teatro em motivo de um desafio central para o pensamento filosófico contemporâneo, na medida em que ele considera que essa relação da filosofia com o teatro implica e estabelece de maneira penetrante a pergunta mesma pela possibilidade da verdade.

O propósito deste artigo é assinalar a produtividade dessa afirmação e de que forma Nietzsche descobriu e desenvolveu semelhante desafio. Praticamente desde as origens do pensamento, um dos problemas filosóficos mais importantes tem sido o de saber se o que percebemos do mundo através dos sentidos é verdadeiro ou ilusório; ou seja, se estamos no mundo do real ou no mundo das meras aparências enganosas. Considera-se que a função da filosofia é justamente delimitar o real e separá-lo do ilusório, ou seja, distinguir a verdade da mentira. Contudo, em relação direta com essa questão, no teatro temos a experiência de um mundo no qual essa distinção não existe. Não nos podemos perguntar se o que vemos em um cenário é verdadeiro ou enganoso, real ou ilusório. Se fizermos essa pergunta, o teatro como tal desaparece porque a condição mesma de seu funcionamento não é outra que a de aceitar de antemão, nele, a não-diferença entre o verdadeiro e o falso, entre o real e o ilusório. $\mathrm{O}$ que nos confirma que, na medida em que sempre houve, ao largo de toda a história, de um modo ou de outro, teatro, isso significa que

1 Foucault, 1978.

28 | Cad. Nietzsche, Guarulhos/Porto Seguro, v.41, n.2, p. 27-43, maio/agosto, 2020. 
A filosofia em cena: crítica e afirmação da teatralidade em Nietzsche

houve então um lugar, um espaço, em que os homens puderam ver as coisas sem considerar a questão de se era verdadeiro ou não o que estavam presenciando.

Foucault enfatiza que uma das originalidades de Nietzsche é pensar dessa forma, ou seja, como a encenação e o teatro foram constituídos como arte. Depois conclui que, no final, o que a filosofia ocidental representa em oposição ao teatro como arte não é outra coisa senão o propósito de construir, diante dele, outro tipo de cena, no seu caso uma certa cenografia da verdade, um novo palco onde as coisas se representem e apareçam de outra forma. Para Nietzsche, o que a filosofia tem significado e representado ao longo da sua história tem sido precisamente isto: um certo teatro do verdadeiro e do falso, muito bem orquestrado e representado de diversas formas, porque, com essa oposição, o Ocidente tem conseguido dominar científica e politicamente o mundo. Esse "teatro da filosofia" teria convertido, assim, o seu palco num campo de batalha entre a verdade e o erro, um confronto dramático exemplar, com um desdobramento muito amplo e variado de estratégias e táticas. A familiaridade de Nietzsche com as grandes figuras e gênios da dramaturgia de sua época lhe permitiu mostrar os grandes confrontos históricos entre essas duas formas de teatro que, até então, passavam despercebidas ou eram desconhecidas. Por um lado, o teatro como arte, no qual não cabe perguntar-se pela distinção entre o verdadeiro e o ilusório. Teatro, pois, como pura representação. E, por outro lado, o teatro da verdade, como exposição e exibição da razão com a qual se consegue compreender o mundo e distinguir o verdadeiro do enganoso aparente.

\section{$O$ interesse de Nietzsche pelo teatro}

Mas de onde Nietzsche retira essa valoração do teatro como uma perspectiva privilegiada para propor toda uma mudança drástica na forma como a filosofia compreendeu-se a si própria desde Sócrates e Platão? Basta assinalar alguns dados para se ter uma ideia da 
formação e preparação que Nietzsche teve nas distintas dimensões da experiência teatral. Em primeiro lugar, ele não apenas foi um aficionado assíduo do teatro como espectador durante a maior parte de sua vida, como também trabalhou ocasionalmente como crítico de teatro, tendo inclusive tentado escrever ele mesmo algumas obras de teatro. Entre elas, destaca-se um drama sobre Empédocles, do qual ainda temos esboços e notas, e que parece querer contrapor àquele que, anos antes, Hölderlin havia escrito sobre esse mesmo filósofo ${ }^{2}$.

Por outro lado, os primeiros trabalhos de Nietzsche baseiamse explicitamente numa longa e poderosa tradição da teoria teatral e dramática alemã, iniciada um século antes com Lessing, e que incluía figuras como Goethe, Friedrich Schiller ou August Wilhelm von Schlegel entre os mais ilustres. Alguns desses autores não só haviam sido teóricos de teatro, mas também dramaturgos eles mesmos, diretores e críticos de teatro. Por isso, essa ampla experiência no campo da produção e da realização teatral repercutiram de modo positivo em suas ideias teóricas. Nietzsche apropriou-se de algumas abordagens desses autores e as completou com suas próprias experiências como crítico e espectador. Devemos acrescentar a sua estreita relação com Richard Wagner durante a sua juventude, que foi, de fato, o que influenciou decisivamente os seus primeiros escritos e fez do seu primeiro livro, O Nascimento da Tragédia, um estudo do teatro grego, especificamente um estudo sobre a tragédia, mas com posicionamentos contínuos sobre o significado artístico das formas teatrais e sobre a necessidade de uma profunda renovação do teatro do seu tempo.

Na verdade, o texto original alemão de Die Geburt der Tragödie está repleto de referências à terminologia cênica: não apenas as palavras drama e teatro, mas Dramatiker (dramaturgo), Schauspiel (drama), Schauspieler (ator) ou Zuschauer (espectadores), para pegar

2 Nietzsche, 2016, Vol. I, p. 132. Para Nietzsche, "a morte de Empédocles foi uma morte por orgulho divino, por desprezo aos homens, pela náusea da terra e por panteísmo. Toda a obra, sua leitura, sempre me comoveu de uma forma especial. Uma superioridade divina vive nesse Empédocles".

30 | Cad. Nietzsche, Guarulhos/Porto Seguro, v.41, n.2, p. 27-43, maio/agosto, 2020. 
A filosofia em cena: crítica e afirmação da teatralidade em Nietzsche

apenas alguns dos termos mais inequívocos, aparecem mais de cem vezes, cada um, ao longo do livro. Também Assim falava Zaratustra oferece claramente uma estrutura dramática em forma de tetralogia, e no resto de suas obras há muitas referências a dramaturgos do passado e do presente. Nelas aparecem, por exemplo, abundantes referências a dramaturgos históricos que marcam sua própria prosa, como Goethe, Schiller ou Shakespeare, mas também Corneille, Racine, Molière, Prospero Mérimée, ou mesmo Lope de Vega e Calderón. O mesmo deve ser dito sobre a presença, em seus escritos, de importantes dramaturgos e críticos de teatro de seu tempo, como Strindberg ou Ibsen, mas outros menos importantes, como Henri Meilhac $^{3}$, dramaturgo e libretista de obras de Offenbach, ou Jules Lemaître, renomado crítico de teatro do Journal des débats, de quem comenta coisas interessantes em sua obra Ecce Homo ${ }^{4}$. De igual modo, suas Cartas revelam não apenas um grande conhecimento do teatro europeu contemporâneo, a partir de leituras de obras teatrais, de revistas e de referências críticas, como também os contatos epistolares diretos que manteve com muitos deles. Encontramos, por exemplo, as interessantes descrições de obras como Os pilares da sociedade, de Ibsen $^{5}$, ou $O$ pai, de Strindberg, que o entusiasmou especialmente e a qual qualificou de "obra mestra da psicologia dura". Em definitivo, os textos de Nietzsche demostram um compromisso com o teatro que está vivo e informado pela prática cênica e pela artesania teatral. Tudo isso confirma a sua dívida para com a tradição teatral alemã do século XVIII e início do século XIX, cujos pressupostos e preocupações centrais ele irá adaptar e reformular em sua obra

3 Nietzsche, 2016, IV, p. 567 e 801. Henri Meilhac escreveu libretos para óperas de Offenbach como La belle Hélène, La Périchole ou La grande-duchesse de Gérolstein.

4 Nietzsche, 2016, IV, p. 801.

5 Nietzsche, 2016, IV, p. 815. Os apelos de Ibsen à igualdade e à liberdade pareciam a Nietzsche meras expressões de "ilusionismo moral".

6 Nietzsche, 2016, IV, p. 570; Nietzsche, 2015, p. 277, p. 286, p. 312, p. 345. Cf. as contribuições de Per Dahl, Carl-Göran Ekerwald, Folke Schimanski, Kai Agthe, Alessandro Fambrini e Heinrich Detering, 2000, pp. 11-101. 
Sánchez Meca, D.

\section{Uma filosofia do teatro}

Nietzsche acusava parte do teatro burguês de seu tempo de ter sido banalizada e reduzida ao mero campo de jogo de pequenas e insignificantes paixões, essencialmente não trágicas ${ }^{7}$. Condena-o como simples paliativo contra o aborrecimento, bem como entretenimento barato que serve para livrar alguém de si mesmo durante algumas horas. Em suma, um lugar de jogo e diversão, e nada além. Assim, seu propósito é tentar recuperar e recriar a maravilha da representação teatral corretamente representada, para a qual acredita ser preciso compreender as condições em que nos comportamos como seres encantados ao nos encontrarmos com essa forma tão especial de arte $^{8}$. Nietzsche aprendeu um ensinamento muito claro sobre o que é a outra forma de prática teatral, distinta daquela que então estava em uso. A que ele imagina no espaço dos teatros gregos e que se lhe impõe como uma alternativa mais potente de arte cênica, a qual deveria ser recuperada, como já haviam apontado Lessing e os neoclassicistas alemães.

Daí o seu entusiasmo primeiro por Wagner, que atribuía a si mesmo, naquele momento, essa recuperação das essências do teatro grego para o século XIX. E depois sua grande decepção, quando considerou que Wagner havia traído esse primeiro propósito para converter-se em um mero empresário dedicado a agradar a um público de filisteus da cultura cada vez mais amplo e, portanto, a ganhar dinheiro. À luz desse desengano, é preciso entender as duras críticas sobre a prática teatral de seu tempo que, em obras como $O$ caso Wagner e Nietzsche contra Wagner, Nietzsche formulou no final de sua vida? . Mas porque Nietzsche já não tinha esperança de ser ouvido. Sentia-se como um crítico teatral que julgava saber como se

7 Para Nietzsche (2016, I, p. 442), o que motiva o burguês contemporâneo a ir ao teatro é "a angustiada fuga do aborrecimento, a vontade de, a todo custo, libertar-se por algumas horas de si mesmo e de sua lamentável condição".

8 Nietzsche, 2016, IV, p. 402.

9 Cf. D. Sánchez Meca, 2018, pp. 252-260

32 | Cad. Nietzsche, Guarulhos/Porto Seguro, v.41, n.2, p. 27-43, maio/agosto, 2020. 
A filosofia em cena: crítica e afirmação da teatralidade em Nietzsche

podia fazer um teatro bem melhor, porém não conseguiu fazer com que aqueles que se dedicavam ao teatro prestassem atenção. A grande retórica antiteatral desses escritos tardios deve ser contextualizada, considerando que muito em breve, poucos anos após sua morte, uma nova geração de dramaturgos e diretores teatrais lhe prestarão atenção e tirarão importantes lições das suas propostas, às quais aludirei adiante.

Um dos primeiros ensinamentos de Nietzsche, que aparece especialmente desenvolvida em sua obra $O$ nascimento da tragédia, refere-se à necessidade de estudar obras dramáticas, tanto antigas como contemporâneas, a fim de forçar uma passagem do drama burguês moderno para o teatro como arte pura. Porque sabe que as raízes do drama burguês moderno devem ser analisadas a partir de sua relação com os seus precedentes clássicos. Diz isso explicitamente em uma das conferencias preparatórias ao livro, intitulada $O$ drama musical grego. Desde logo, é preciso descobrir "a relação genealógica" do teatro burguês europeu com seus predecessores gregos ${ }^{10}$. Desse estudo, Nietzsche extrai duas ideias importantes: uma relativa aos componentes essenciais do teatro como forma artística, e outra em relação a seu significado filosófico de fundo e a seu valor cultural. Quanto à primeira, está claro que as grandes tragédias gregas foram concebidas inteiramente tendo em vista ser encenadas. Ou seja, foram escritas para o palco, para ser representadas ao vivo ante um auditório numeroso por ocasião dos grandes festivais. Portanto, seu autêntico significado é inseparável de sua realização cênica. Isto é, não se pode captar o sentido dessa forma de arte se se atém apenas a seus elementos narrativos, ou seja, se simplesmente se lê o libreto, como fazem os filólogos clássicos.

10 “Em nosso teatro atual não só se podem encontrar memórias e ressonâncias das artes dramáticas da Grécia: não, as formas fundamentais de nosso teatro estão enraizadas no solo helênico" (Nietzsche, 2016, I, p. 439). Nietzsche antecipa nessa página as linhas que mais tarde serão o primeiro uso declarado da genealogia como termo metodológico e procedimento de investigação. 
Essa tinha sido a ideia que também Wagner defendia quando Nietzsche o conheceu, ou seja, uma forma de teatro na qual um conjunto de artes individuais se une em um todo inseparável para dar lugar a uma nova forma de arte. É, portanto, consubstancial ao teatro como arte a fusão em uma unidade do textual e do físico. Porque o teatro, diz Nietzsche, invoca os sentidos, envolve os corpos de seus espectadores e os conduz para novos estados afetivos, de modo que, com todo esse envolvimento sensorial, é capaz de intensificar os poderes da vida em uma experiência totalizadora extraordinária:

Há uma simpatia universal pela tese estética de que a união de duas e mais artes não pode produzir nenhuma elevação do prazer estético, ao contrário, é uma bárbara aberração do gosto. Mas essa tese demonstra, no máximo, o mau costume moderno de que já não podemos desfrutar como seres humanos inteiros: estamos, por assim dizer, desfeitos em fragmentos pelas artes absolutas e agora apreciamos também como fragmentos, ou como seres humanos convertidos em ouvidos, ou como seres humanos convertidos em olhos, etc. Comparemos com isso como o engenhoso Anselm Feuerbach representa aquele drama antigo como arte total. "Não é de estranhar, diz, que, dada essa afinidade eletiva profundamente enraizada, as artes individuais acabem fundindo-se de novo em um todo inseparável, como uma nova forma de arte"... É certo que só diante de tal obra de arte devemos aprender como apreciá-la como seres humanos inteiros ${ }^{11}$.

Porque, do mesmo modo que o teatro é uma arte das palavras, também é do tom e do som da linguagem, das aparências figurativas e das visões representadas. Nietzsche resume afirmando que é a arte na qual todo o ouvido está acompanhado por algo visto, e todo o compreendido está acompanhado por algo experimentado. Essa reunião de distintas artes (cenografia, vestuário, atuação, recitação, música e dança), própria das tragédias gregas, perdeu-se no tempo, restando apenas o libreto, ou seja, o esqueleto dramático para que os eruditos o aproveitem. O que Nietzsche considera então é que

$\overline{11 \text { Nietzsche, 2016, I, p. } 441}$ 
as partes mais desconhecidas da tragédia grega são, na verdade, as mais importantes para compreender, não só sua antiga forma original, como o sentido mesmo da forma teatral como arte.

Nietzsche oferece, então, uma análise detalhada dessa ideia de teatro como arte, que, segundo ele, é inerente realizar-se em três dimensões: a do ator, a do poeta ou escritor do texto e a do espectador $^{12}$. Esses três papéis, em seu sentido mais amplo, seguem sendo centrais para toda empresa teatral e o ponto de apoio do teatro como autêntica forma artística. E é a conjunção desses três papéis que é capaz de produzir o potente encantamento teatral a que Nietzsche se refere várias vezes. $\mathrm{O}$ ator é aquele que empresta seu corpo em sua totalidade para sua execução, na qual o espectador pode usar a imaginação de sua própria participação. Empresta, portanto, seu ser à atividade do dramaturgo-poeta. Esse poeta, por sua vez, é quem prepara o ator para tal encarnação, moldando com seu texto não apenas o caráter e a ação do ator, como também, o que é mais importante, sua aparência, seu gesto e o som de sua voz. Vale dizer, toda sua presença no palco. Por último, o espectador é muito mais que o mero receptor passivo da arte do ator e do poeta. Na realidade, é o participante central, a fonte de toda a representação teatral e de seu significado último:

Aqui está o berço do drama - diz Nietzsche -, pois este não começa com alguém que se mascara e quer provocar um engano nos outros: não, ao contrário, na medida em que o ser humano está fora de si e se crê transformado e enfeitiçado. Na condição de "estar fora de si", no estado de êxtase, já não é necessário senão dar um passo: não retornamos a nós mesmos, mas entramos em outro ser, de maneira que nos portamos como enfeitiçados. Daí provém, em última instância, a profunda estranheza ante a visão do drama: o chão deixa de ser seguro, se abala a crença na insolubilidade e fixidez do indivíduo. E de igual modo que... o entusiasta

$12 C f$. Nietzsche, 2106, I, p. 442 ss. 
Sánchez Meca, D.

dionisíaco crê em sua transformação, assim também o poeta dramático crê na realidade de seus personagens ${ }^{13}$.

Eis por que Nietzsche critica o conceito de teatro predominante em seu tempo, que se havia despojado em boa medida de seu autêntico caráter de arte para colaborar com o grande teatro da verdade desenvolvido pela filosofia. O que importava era que, também no teatro, o espectador aprendera a distinguir o verdadeiro do falso ou que se comovesse pelo triunfo do bem sobre o mal. Assim, podia ter o mesmo efeito ser simplesmente lido ou representado, fazendo da encenação algo não essencial. O teatro burguês tinha se contaminado, como já em Eurípides, pela influência desse desejo de verdade e de moralidade que a filosofia vinha promovendo desde os tempos antigos. Contudo, o teatro como autêntica forma artística deve estar longe desse propósito filosófico, pois seu fundamento é mostrar de maneira artisticamente potencializada um acontecimento que, como sucede na vida, não é a priori nem verdadeiro nem falso, nem bom nem mau, mas algo que acontece na superfície do tempo como simples aparecer e representar-se. Algo que, uma vez encenado, não sobra nada. $\mathrm{O}$ teatro, portanto, como uma profunda intuição, artisticamente potencializada, do sentido último do que acontece e do que somos, intuição que não é a da filosofia, mas que é combatida por ela.

Nietzsche pode concluir, pois, que o teatro antigo era o que mostrava a verdadeira sabedoria, adotando a forma de um sutil equilíbrio entre a superfície e a profundidade. Os gregos, diz Nietzsche em A gaia ciência, e repete também em Nietzsche contra Wagner, eram superficiais desde a profundidade: "Oh, esses gregos! Eles sim que sabiam viver! Para isso é preciso manter-se firme na superfície, na dobra, na pele, adorar a aparência, crer nas formas, nos sons, nas palavras, em todo o Olimpo da aparência! Esses gregos eram

13 Nietzsche, 2016, I, p. 444

36 | Cad. Nietzsche, Guarulhos/Porto Seguro, v.41, n.2, p. 27-43, maio/agosto, 2020. 
A filosofia em cena: crítica e afirmação da teatralidade em Nietzsche

superficiais - por profundidade" (FW/GC, Prólogo, 4). ${ }^{14}$ De fato, seu gênio consistiu em ter sido capazes de mostrar na superfície de uma encenação artística, fugaz e rápida, a profundidade da insubstancialidade de nosso ser e de tudo o que nos acontece.

Em qualquer caso, o que de Nietzsche aprendem os novos dramaturgos do Século XX será essa inversão na compreensão da prática teatral. Não se pode compreender nenhum gênero dramático adequadamente à margem das condições de sua encenação. Portanto, não se pode articular nenhuma teoria dramática que não seja também das condições de sua encenação. É assim porque o significado no teatro não pode ser extraído só das palavras da obra, mas da contemplação intensa e da experiência de sua encenação.

\section{Breve nota sobre a influência de Nietzsche na transformação das práticas cênicas do teatro contemporâneo}

Hoje já se conhece bem a recepção que Nietzsche teve entre alguns dramaturgos importantes do século XX, que se deixaram influenciar, em maior ou menor medida, por suas ideias sobre o teatro. É possível documentar que essa aceitação do pensamento teatral de Nietzsche foi bastante mais extensa, rica e elaborada do que em princípio parecia ser. Seus pontos de vista singulares representaram um revulsivo poderoso, não só para as distintas formas de fazer filosofia em seu tempo, coisa de que já ninguém duvida, mas também para as práticas teatrais de autores como August Strindberg, George Bernard Shaw ou Eugene O'Neill, que por aqueles anos buscavam novas formas e novos significados para sua arte. A evolução de Strindberg, por exemplo, do naturalismo ao expressionismo, ou a de Shaw, que apelava para um drama de ideias ibsenistas, ou o movimento de O'Neill, distante da experimentação expressionista para aproximar-

14 Nietzsche, 2016, IV, p. 922; Cf. também 2016, III, p. 721 
Sánchez Meca, D.

se de um realismo poético: os três encontram em Nietzsche ideias interessantes para uma redefinição do teatro e da experimentação dramatúrgica. E isto na medida em que alguns dos princípios gerais do que poderíamos chamar de drama contemporâneo começam a ser formulados e a tomar forma nos e através dos esforços teatrais e dos experimentos dramáticos desses autores.

Strindberg, por exemplo, que foi um dos primeiros a ler Nietzsche quando ele ainda era pouco conhecido, muda quase por completo sua concepção de cenário como resultado dessas leituras. Destaca-se sua tensa e devastadora obra Senhorita Júlia. Sabemos que essa obra foi concebida quando Strindberg leu $O$ caso Wagner, de Nietzsche. E que muitos de seus argumentos, inclusive algumas de suas notas de rodapé, foram usadas depois por Strindberg em seus ensaios para defender a necessidade de novos rumos artísticos para o drama ${ }^{15}$. Quanto a George Bernard Shaw, ele se tornou um dos principais divulgadores dos escritos de Nietzsche na Inglaterra. Algumas das posições intelectuais e ideológicas do filósofo foram claramente dramatizadas por Shaw em sua obra Major Bárbara. E naqueles anos em que Nietzsche era ainda muito pouco conhecido na Inglaterra, Shaw elegeu passagens de $O$ nascimento da tragédia para compor uma Antologia cuja publicação alcançou uma ampla difusão ${ }^{16}$. Por sua parte, Eugene O’Neill foi o autor que levou Nietzsche para a Broadway. É conhecida a anedota desse autor que, em sua primeira entrevista a seu biógrafo, o presenteou com um exemplar de $O$ nascimento da tragédia, de Nietzsche, para mostrar-lhe que estava profundamente em dívida com esse livro. Quase todos os ensaios publicados de O'Neill sobre o teatro fazem referência direta ou indireta a ele, e recapitulam alguma versão de suas ideias. Provavelmente sua obra Longa jornada noite adentro ${ }^{17}$ é a que mostra melhor o que

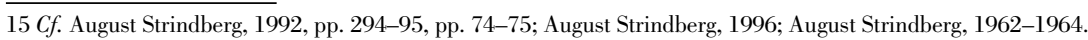
16 George Bernard Shaw, 2002; George Bernard Shaw, 1991, pp. 226-229; George Bernard Shaw, 1958, 1972. 17 Eugene O’Neill, 1989, 1987, 1988.

38 | Cad. Nietzsche, Guarulhos/Porto Seguro, v.41, n.2, p. 27-43, maio/agosto, 2020. 
A filosofia em cena: crítica e afirmação da teatralidade em Nietzsche

O'Neill recebe de Nietzsche, porque inclusive frases da obra de Nietzsche podem ser ouvidas na boca de alguns de seus personagens ${ }^{18}$. Portanto, Senhorita Júlia, Major Bárbara e Longa jornada noite adentro, ou seja, obras representativas do cenário do século XX, foram escritas à luz, em referência ou inclusive inspirando-se diretamente nas ideais de Nietzsche sobre o teatro. Por certo que esse impacto de Nietzsche foi muito mais amplo do que esses três autores representam. Ibsen, por exemplo, conheceu Nietzsche, ainda que não seja certo se diretamente ou através das conferências de Brandes ${ }^{19}$. William Butler Yeats foi outro importante autor influenciado por Nietzsche, tanto em sua poesia como em seu drama, depois de lê-lo pela primeira vez em $1903^{20}$. E outros com casuísticas bem variadas, como é o caso de Luigi Pirandello, que leu Nietzsche quando simpatizava com o fascismo de Mussolini, e que transferiu para suas obras o condicionamento e a distorção que esse encontro produziu em sua $\operatorname{arte}^{21}$. O filósofo que todos esses artistas descobriram pareceulhes ativamente comprometido com a necessidade de uma reforma profunda do teatro. Poder-se-ia dizer que o drama no século XX, além de dar ao público a oportunidade de participar de um modo particular de pesquisa social, vai ao encontro de uma ampla reformulação do acontecimento teatral, o que implica importantes modificações, não apenas na estrutura do drama, como também a tudo relacionado com a sua encenação. De maneira mais específica, o desenvolvimento do drama contemporâneo está marcado, ao menos em parte, pela eliminação da divisão entre o textual e o teatral. Ou seja, a nova obra não só é um veículo narrativo, como também uma ferramenta para projetar o espaço teatral mesmo, de modo que o que se comunica

\footnotetext{
$18 C f$. Egil Törnqvist, 2004

19 Cf. Toril Moi, 2008, pp. 196-197; Elinor Fuchs, 1996, p. 64; Evert Sprinchorn, 1972, pp. 58-79; Thomas F. Van Laan, 2006, pp. 255-302.

20 Cf. Michael McAteer, 2010; Patrick Bridgwater, 1972, cap. “That Strong Enchanter”, pp. 67-90.

21 William Murray, 1970; Bruno Romano, 2008; Michael Rössner, 1984, pp. 9-25.
}

Cad. Nietzsche, Guarulhos/Porto Seguro, v.41, n.2, p. 27-43, maio/agosto, 2020.| 39 
Sánchez Meca, D.

nela só pode ter lugar no momento e no espaço de sua performance ${ }^{22}$. Uma das coisas, portanto, que tiveram em comum esses artistas que experimentaram com formas de teatro muito distintas no século $\mathrm{XX}$, foi algumas ideias inovadoras de procedência nietzschiana. $\mathrm{O}$ que permite concluir que o que descobriram em Nietzsche foi um pensador entusiasmado com uma revolução nas práticas da encenação, mas ao mesmo tempo um crítico apaixonado pelo potencial de uma forma de arte que ele sentia que se interpretava em sua época de maneira diminuída.

22 Cf. Austin Quigley, 1985; David Krasner, 2011; Ric Knowles, Joanne Tompkins, W. B. Worthen, 2003.

40 | Cad. Nietzsche, Guarulhos/Porto Seguro, v.41, n.2, p. 27-43, maio/agosto, 2020. 


\title{
Philosophy at Stage: Criticism and Statement of Theatricality in Nietzsche
}

\begin{abstract}
The purpose of this article is to show the contribution of Nietzsche to the revolution in the practices of the scenario that takes place in the 20th century, as well as its relevance as a passionate critic for the potential of an art form that he felt was interpreted in his time in a diminished way. From his study of Greek theater in his work The Birth of Tragedy, he underlines the importance that in the ancient tragedy had its staging, and that went beyond the text written by its author. It offers therefore an analysis of the idea of theater as art, which is consubstantial in three dimensions: the actor, the poet or writer of the text and the viewer. Nietzsche defends the specificity of these three roles for every theatrical enterprise and the philosophical sense that theater has as an authentic artistic form. The article concludes by showing the acceptance of Nietzsche's theatrical thought in authors such as August Strindberg, George Bernard Shaw or Eugene O'Neill, who sought new forms and new meanings for their art.
\end{abstract}

Keywords: Theater, Nietzsche, Philosophy, Art, Staging.

\section{Referências}

BOGARD, Travis; BRYER, Jackson R. (eds.). Selected Letters of Eugene O'Neill. New Haven: Yale University Press, 1988.

BRIDGWATER, Patrick. Nietzsche in Anglosaxony. Leicester: Leicester University Press, 1972.

DAHL, Per et al. Widersprüche. Zur frühen Nietzsche-Rezeption. A. Schirmer e R. Schmidt (eds.). Weimar: Hermann Böhlaus Nachfolger, 2000.

FOUCAULT, M. La scène de la philosophie : entrevista con M. Watanabe (22 de abril de 1978). Sekai, julho 1978.

FUCHS, Elinor. The Death of Character: Perspectives on Theater after Modernism. Bloomington: Indiana University Press, 1996. 
Sánchez Meca, D.

KNOWLES, Ric; TOMPKINS, Joanne; WORTHEN, W. B. (eds.). Modern Drama: Defining the Field. Toronto: University of Toronto Press, 2003.

KRASNER, David. A History of Modern Drama. Hoboken: Wiley-Blackwell, 2011.

MCATEER, Michael. Yeats and European Drama. Cambridge: Cambridge University Press, 2010.

MOI, Toril. Henrik Ibsen and the Birth of Modernism: Art, Theater, Philosophy. Oxford: Oxford University Press, 2008.

MURRAY, William Pirandello’s One-Act Plays. New York: Samuel French, 1970.

NIETZSCHE, F. Sämtliche Werke. Kritische Studienausgabe (KSA). (Organizada por Giorgio Colli e Mazzino Montinari). Berlim: Walter de Gruyter \& Co., 1988. 15 vols.

. Brief an meinen Freund, in dem ich ihm meinen Lieblingsdichter empfehle. In: Historisch-kritische Gesamtausgabe. Werke. Band 2: Jugenschriften. Herausgegeben von Joachim Mette. München: dtv, 1994.

. Correspondencia. L. de Santiago (ed.). Madrid: Trotta, 2015. 7 vols.

. Obras Completas. $2^{\mathrm{a}}$ ed. Diego Sánchez Meca (ed.). Madrid: Tecnos, 2016. 4 vols

O'NEILL, Eugene. Comments on the Drama and the Theater: A Source Book. Ulrich Halfmann (ed.). Tübingen: Günter Narr, 1987.

1989.

Long Day's Journey into Night. New Haven: Yale University Press,

QUIGLEY, Austin. The Modern Stage and Other Worlds. London: Methuen, 1985.

ROMANO, Bruno. Nietzsche e Pirandello: il nichilismo mistifica gli atti nei fatti. Turín: Giappichelli, 2008.

RÖSSNER, Michael. Nietzsche und Pirandello. Parallelen und Differenzen zweier Denk-Charaktere. In: THOMAS, Johannes (ed.). Pirandello-Studien: Akten des 1. Paderborner Pirandello-Symposiums. Paderborn: Schöningh, 1984, pp. 9-25.

SÁNCHEZ MECA, D. El itinerario intelectual de Nietzsche. Madrid: Tecnos, 2018.

42 | Cad. Nietzsche, Guarulhos/Porto Seguro, v.41, n.2, p. 27-43, maio/agosto, 2020. 
A filosofia em cena: crítica e afirmação da teatralidade em Nietzsche

SHAW, George Bernard. To Audiences at Major Barbara. In: Shaw on Theatre. E. J. West (ed.). New York: Hill and Wang, 1958. 1972. . Collected Letters 1898-1910. Dan H. Laurence (ed.). New York: Dodd,

SHAW, George Bernard. Our Book-Shelf: "Friedrich Nietzsche: The Dionysian Spirit of the Age”. In: Bernard Shaw's Book Reviews. vol. 2. Brian Tyson (ed.). University Par: Penn State University Press, 1991. 2002.

.George Bernard Shaw's Plays. Sandie Byrne (ed.). New York: Norton,

SPRINCHORN, Evert. Ibsen and the Immoralists. Comparative Literature Studies, 9, 1, pp. 58-79, março 1972.

STRINDBERG, August. August Strindbergs dramer. Carl Reinhold Smedmark (ed.). Stockholm: Bonniers, 1962-1964. 3 vols

.Strindberg's Letters. vol. 1 (1862-1892). Michael Robinson (ed.). London: Athlone, 1992.

. Strindberg on Drama and Theatre: A Sourcebook. Egil Törnqvist e Birgitta Steene (eds.). Amsterdam: Amsterdam University Press, 2007.

. Selected Essays. Michael Robinson (ed.). Cambridge: Cambridge University Press, 1996.

TÖRNQVIST, Egil. Eugene O'Neill: A Playwright's Theatre. Jefferson: McFarland, 2004.

VAN LAAN, Thomas F. Ibsen and Nietzsche. Scandinavian Studies, 78, 3, pp. 255-302, Fall 2006.

Recebido: 27/11/2019

Aceito: 15/01/2020 